Article

\title{
Effect of High Mixing Intensity on Rheological Properties of Cemented Paste Backfill
}

\author{
Liuhua Yang ${ }^{1,2, *} \mathbb{B}$, Hongjiang Wang ${ }^{1, *}, \operatorname{Hong~Li}^{1}$ and $\mathrm{Xu}$ Zhou ${ }^{1}$ \\ 1 School of Civil and Resource Engineering, University of Science and Technology Beijing, \\ Beijing 100083, China; lihongzx1@126.com (H.L.); pedrozhxu@gmail.com (X.Z.) \\ 2 Institut für Keramik, Glas-und Baustofftechnik der TU Bergakademie Freiberg, 09599 Freiberg, Germany \\ * Correspondence: yanglh2005@163.com (L.Y.); b20150043@xs.ustb.edu.cn (H.W.); \\ Tel.: +86-010-62334680 (L.Y.); Tel.: +86-010-62333864 (H.W.)
}

Received: 13 March 2019; Accepted: 10 April 2019; Published: 18 April 2019

check for updates

\begin{abstract}
Cemented paste backfill (CPB) consists of a mixture of fine particles, mainly consisting of tailings and cement dispersed in water. Therefore, it is necessary to introduce an intensive shearing force into the paste during mixing in order to maintain an equilibrium between agglomeration and dispersion. It is influential for the macroscopical fluidity and rheological properties when changes occur in the microstructure of $\mathrm{CPB}$ under shear. However, the research on how mixing affects the properties of CPB is still in its infancy. This paper puts an insight into the relation between the mixing intensity and the rheological behavior of the CPB. It can be demonstrated that two threshold mixing intensities exist in this process. After passing the first or lower threshold, the rheological parameters (yield stress and viscosity) of the paste decrease. After passing the second threshold, a continued increase is observed. The changes in rheological properties are connected with physical and chemical changes in the microstructure of the $\mathrm{CPB}$. The results are discussed in light of the three concepts "structural breakdown", "thixotropic breakdown", and "thixotropic behavior" of rheological properties of CPB.
\end{abstract}

Keywords: rheology; microstructure; flow behavior; cemented paste backfill; mixing

\section{Introduction}

A growing interest is being paid to the rheological behavior of concentrated suspensions [1], such as cemented paste backfill (CPB), in both theoretical and applied fields. CPB is a mixture of unclassified tailings, crushed aggregates, powder, water, and chemical admixtures [2,3]. CPB technology is also considered superior to conventional slurry backfill methods in terms of both the environmental and economic benefits [4]. These components are generally blended on the surface of a mine and then transported by gravity or pumped to the underground goaf [5]. In the cemented backfill, mixing is an essential process for the acquisition and management of the properties of backfilling materials [6]. More than homogenizing the paste constituents, it plays an important role in characterizing the rheological properties of fresh CPB $[7,8]$. As the paste backfilling technology has already been a priority option for tailings disposal under policies emphasizing environmental conservation, improper mixing is currently one of the urgent concerns for mining engineers $[9,10]$. The aim of minimizing the mixing intensity and mixing time without damaging the quality and productivity is widely pursued [11], even in the cementitious materials related industries [12]. Hence, a well-designed mixing technique is crucial for CPB preparation.

As a complex of tailings, cement, and water, CPB is a kind of granular fluid and which, when in fresh state, could be regarded as a suspension of tailing particles suspended in the slurry $[13,14]$; however, the slurry is not even heterogeneous due to the existence of abundant cement particles and 
hydrates. Therefore, the rheological properties and macroscopic flow behavior of CPB are significantly influenced by the internal structure of the paste matrix $[15,16]$. Consistent with other concentrated suspensions, CPB also has the rheological properties of yielding, shear thickening, shear thinning, rheopexy, and thixotropy $[17,18]$. When under shearing, the intrinsic network structure of CPB responds to the shear-induced stresses with the interference of interparticle forces, leading to changes in the rheological behavior [19]. Thus, to understand the influence mechanism of mixing speed on the properties of $\mathrm{CPB}$ is a priority for the improvement of the mixing technique. Under different mixing intensities, CPB specimens tend to present different rheological properties. The phenomenon is affected by the interparticle forces, and it could be explained by the Particle Flow Interaction theory (PFI-theory), which consists of several coupled partial differential equations (PDEs) and is well explained in previous studies [20]. These equations describe the processes of coagulation, dispersion, and re-coagulation of the particles (giving a true thixotropic behavior) [21]. The microstructural changes that lead to thixotropy are called thixotropic breakdown. These concepts were proposed by Hattori and Izumi [22,23] and by Tattersall and Richie [24,25], respectively.

In the PFI-theory, the thixotropic behavior has a relation to coagulation, dispersion, and re-coagulation of the particles, where the coagulation refers to the touch between two or more particles. In order to improve the technological properties of $C P B$, the particles need to be separated which poses a challenge to CPB mixing. These particles are forced together by their total potential energy, as illustrated in Figure 1, where the term $D_{\mathrm{s}}$ is the distance between two solid surfaces of the particles [26]. The total potential energy interaction $V_{\mathrm{T}}$ originates from combined forces of van der Waals attraction, steric hindrance, and electrostatic repulsion [27]. Under a shear force that is larger than the $V_{\mathrm{T}}$, the particles will be separated and the rheological properties of CPB decrease, which is called thixotropic breakdown [28].

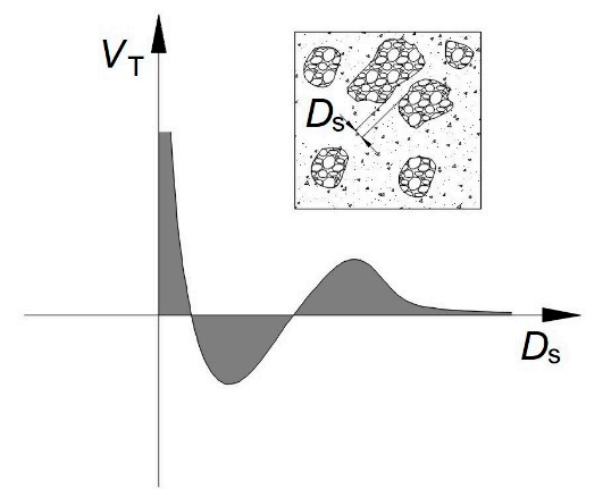

Figure 1. Total potential energy interaction $V_{\mathrm{T}}$ between particles.

The structural breakdown phenomenon seems to be rarely mentioned compared to the well-known thixotropy. Since no recovery of torque was observed, structural breakdown was considered to be different from thixotropic breakdown [29]. As mentioned in the previous paragraph, thixotropic breakdown is related to behavior generated by the total potential energy that exists between particles, while the structural breakdown is not [30]. It is attributed to the shrinking electric double layer of cement particles and/or breaking the connections between the particles formed by the hydration process [31]. That is, when the cement was added to the mixer and contacted with water, the hydration product covers the surface of the particles in the form of membrane [32], causing the particles to contact together. As the CPB is mixed, this connection between the particles is broken and the particles are separated. If the mixing intensity is high enough, the shrinking electric double layer will also occur and the chemical environment of CPB will be changed [33]. Currently, it is the complexity of the intrinsic network structure and the interparticle interactions that make the mixing theory lag behind its application $[34,35]$. 
The paste is generally produced by blending the constituents and then transforming the mixture from a wet granular state into a granular suspension microstructure. The high-intensity mixing technology of CPB (without crushed aggregates) usually includes two steps, as shown in Figure 2 [36], where the tailings are firstly mixed with binding materials to form a stiff paste that is similar to a conventional concrete mixing process, and then the high-intensity mixing is applied to make the paste become soft or fluid. This technology allows the CPB to possess a better performance while the mechanism of action is still unclear. Therefore, the impact and its mechanism of varying blending intensities on the rheological properties of fresh $\mathrm{CPB}$ were investigated, providing some theoretical support for further development of the high-intensity mixing technology.

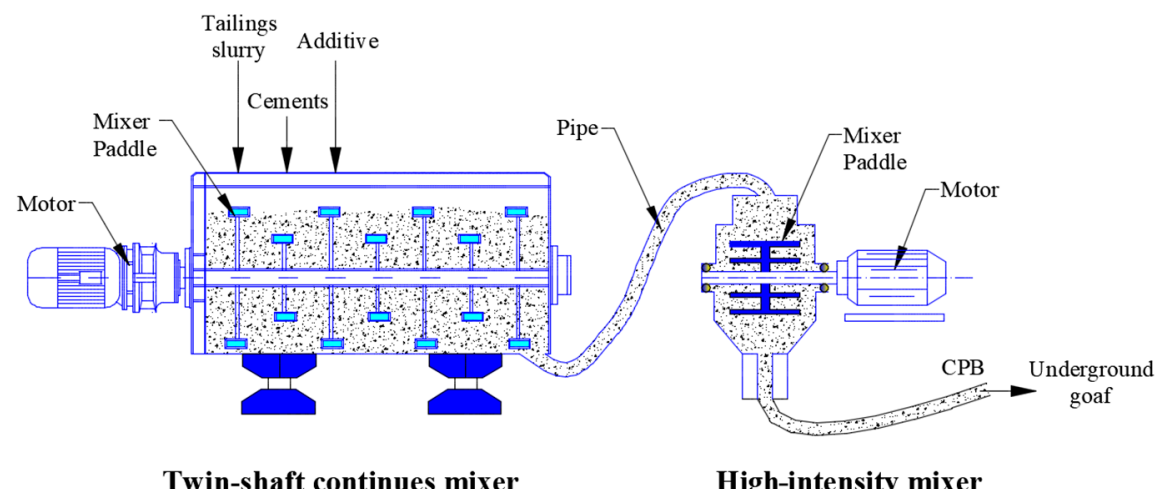

Figure 2. The high-intensity mixing technology of cemented paste backfill (CPB).

\section{Materials and Methods}

\subsection{Materials}

\subsubsection{Tailings}

The tailings sampled to prepare $\mathrm{CPB}$ were the full process tailings obtained from a copper mine, of which the specific gravity was 2.69. The chemical characteristics of the tailings were analyzed by X-ray fluorescence (XRF) (NEX CG, Rigaku International Corp., Tokyo, Japan) and are shown in Table 1.

Table 1. Chemical characteristics of the tailings.

\begin{tabular}{ccccccccccc}
\hline Compound & $\mathbf{P b}$ & $\mathbf{Z n}$ & $\mathbf{S}$ & $\mathbf{A s}$ & $\mathbf{A u}$ & $\mathbf{A g}$ & $\mathbf{C a O}$ & $\mathbf{M g O}$ & $\mathbf{A l}_{2} \mathbf{O}_{3}$ & $\mathbf{S i O}_{2}$ \\
\hline Content $/ \%$ & 0.035 & 0.003 & 0.39 & 0.057 & 0.03 & 1.59 & 9.16 & 1.4 & 6.19 & 64.69 \\
\hline
\end{tabular}

The particle size distribution is shown in Figure 3 which was tested with a Topsizer 2000 Laser Particle Characterization System made by OMEC, Ltd., (Zhuhai, China). The measurement covers a range of 0.02 to $2000 \mu \mathrm{m}$, with $1 \%$ precision. It was observed that the fine particles $(<20 \mu \mathrm{m})$ accounted for about $29.98 \mathrm{wt} \%$ and the tailings could be classified as coarse tailings [37].

\subsubsection{Cement}

The components of the cement used (obtained by X-ray fluorescence (XRF)) are shown in Table 2, and the cement belongs to ordinary Portland cement (OPC) CEMI 32.5R type. The main chemical components of the cement were $\mathrm{CaO}$ and $\mathrm{MgO}$, and a small amount of $\mathrm{K}_{2} \mathrm{O}$. The Blaine fineness was $402 \mathrm{~m}^{2} / \mathrm{kg}$ and specific gravity 3.14 , according to the cement factory report.

Table 2. Characteristics of the cement.

\begin{tabular}{ccccccccc}
\hline Items & $\mathbf{M g O}$ & $\mathrm{SiO}_{2}$ & $\mathrm{Na}_{2} \mathbf{O}$ & $\mathbf{K}_{\mathbf{2}} \mathbf{O}$ & $\mathbf{A l}_{2} \mathbf{O}_{3}$ & $\mathbf{S O}_{3}$ & $\mathrm{Fe}_{2} \mathbf{O}_{3}$ & $\mathbf{C a O}$ \\
\hline Amount (\%) & 1.40 & 20.70 & 0.18 & 0.48 & 4.50 & 2.60 & 3.30 & 65.10 \\
\hline
\end{tabular}




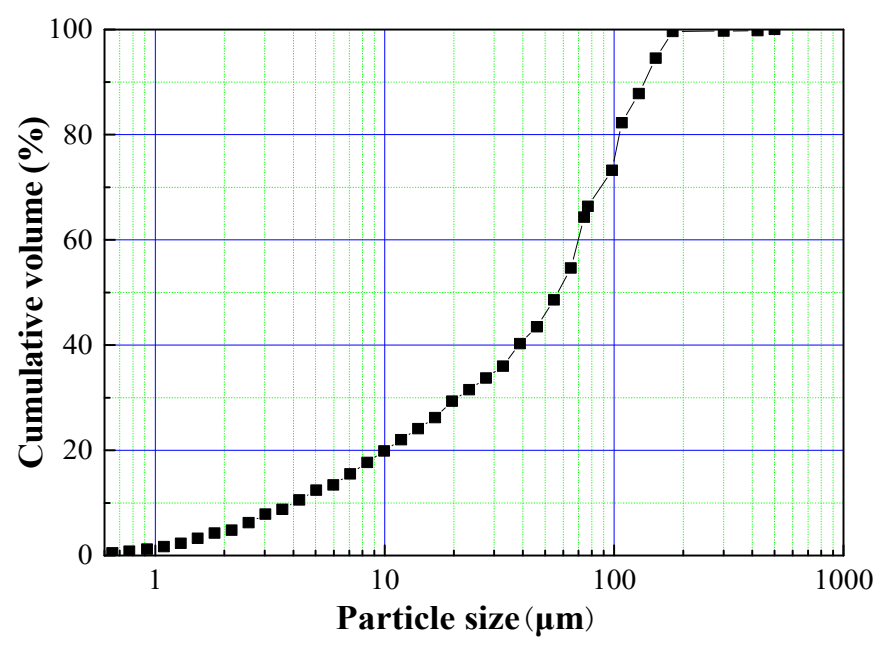

Figure 3. Particle size distribution of the unclassified tailings.

\subsection{Mixture Contents}

The CPB samples were produced using deionized water. The proportions are provided in Table 3 where four kinds of $\mathrm{CPB}$ of three different solid contents and a constant water-cement $(w / c)$ ratio of 2.75 were tested in $\mathrm{CPB}-\mathrm{A}, \mathrm{CPB}-\mathrm{B}$, and $\mathrm{CPB}-\mathrm{C}$, and a relatively low water-cement $(w / c)$ ratio of 2.25 was tested in CPB-D. The $t / c$ refers to the tailings-to-cement ratio and is based on the mass of tailings versus the mass of cement. Composition of different CPB samples is given in Table 3.

Table 3. Mixture proportions of CPB.

\begin{tabular}{cccccc}
\hline Code & $\begin{array}{c}\text { Water } \\
\boldsymbol{w} / \boldsymbol{c} \text { (by mass) }\end{array}$ & $\begin{array}{c}\text { Cement } \\
\mathbf{( w t} \mathbf{\%})\end{array}$ & $\begin{array}{c}\text { Tailings } \\
\boldsymbol{t} / \boldsymbol{c} \text { (by mass) }\end{array}$ & $\begin{array}{c}\text { Solids Content } \\
\mathbf{( w t} \text { \%) }\end{array}$ & $\begin{array}{c}\text { Solids Content } \\
\text { (vol. \%) }\end{array}$ \\
\hline CPB-A & 2.75 & 8.12 & 8.56 & 77.66 & 56 \\
CPB-B & 2.75 & 8.64 & 7.83 & 76.25 & 54 \\
CPB-C & 2.75 & 9.17 & 7.16 & 74.79 & 52 \\
CPB-D & 2.25 & 11.17 & 5.70 & 74.86 & 52 \\
\hline
\end{tabular}

\subsection{Preparation of Samples}

In the experiment, a cement mortar mixer was used for initial mixing, and a high-shearing-type mixer as shown in Figure 4 was used for secondary mixing, where the velocity was under control of the pre-set computer programs at a room temperature of $20^{\circ} \mathrm{C}$. The equipment, as illustrated in Figure 4 , includes a glass bottle containing $\mathrm{CPB}$, a mixer, and a control computer. It is not trivial to measure the shear rates of CPB samples in the mixer, with a rotary propeller approximate value (Equation (1)) [38], however, an indication of the value of the shear rate applied to the mixture in the mixing vessel at varying intensity was evaluated, as shown in Table 4.

$$
\dot{\gamma}=\frac{2 r_{a} r_{b} \omega}{\left(r_{b}^{2}-r_{a}^{2}\right)}
$$

where $r_{a}$ is the radius of the rotary propeller (here referred to that of the mixer blade), $r_{b}$ is the radius of the container (here referring to the CPB mixer vessel), and $\omega$ represents the angular velocity of the blades. It is illustrated in Figure 4 that $r_{a}=60 \mathrm{~mm}$ and $r_{b}=55 \mathrm{~mm}$. Similarly, the shear rate of the high-intensity mixing technology could be calculated according to the geometrical parameters of the mixer, as shown in Table 4 . As the speed of the high-intensity mixing of CPB was generally controlled between 1000 and $2000 \mathrm{rpm}$, the mixing speed of the high-shearing-type mixer was not more than $600 \mathrm{rpm}$ in the study according to Table 4. 


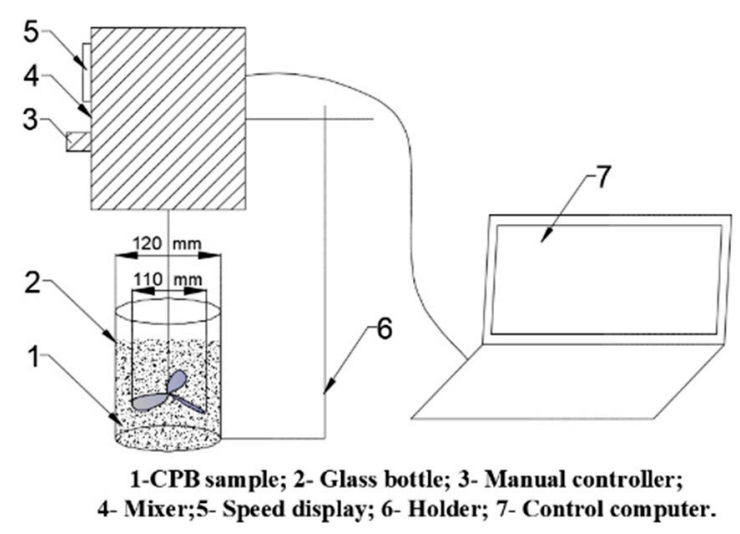

Figure 4. High-shearing-type mixer.

Table 4. Estimated shear rate of the high-shearing-type mixer and high-intensity mixer.

\begin{tabular}{ccc}
\hline High-Shearing-Type Mixer (rpm) & High-Intensity Mixer (rpm) & Estimated Shear Rate $\left.\mathbf{( s}^{\mathbf{- 1}}\right)$ \\
\hline 100 & 334.78 & 120.14 \\
200 & 669.57 & 240.28 \\
300 & 1004.35 & 360.42 \\
400 & 1339.13 & 480.56 \\
500 & 1673.91 & 600.70 \\
600 & 2008.70 & 720.83 \\
\hline
\end{tabular}

A sequence consisting of four steps was designed for the CPB mixing to better simulate the high-intensity mixing technology, which is illustrated in Figure 5. In Step 2, a relatively low speed (75 rpm) was set for the initial mixing (using the cement mortar mixer) to highlight the differences in the rheological behavior of CPBs under different mixing intensities at Step 4 (using the high-shearing-type mixer), specifically 75, 200, 300, 400,500, and $600 \mathrm{rpm}$. After the initial three steps, the paste should have been sufficiently homogenized, and Step 4 was designed to measure how the high mixing speed affects the CPB samples.

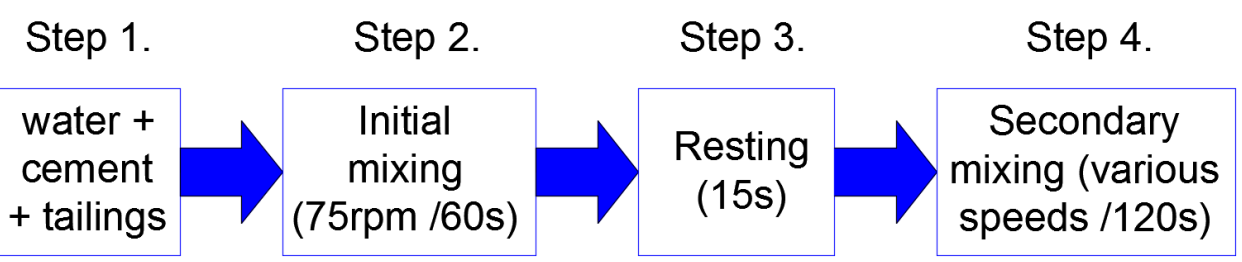

Figure 5. Mixing treatment to prepare CPB. Mixing speeds ranged from 75, 200, 300, 400, 500, and $600 \mathrm{rpm}$ for Step 4.

\subsection{Experimental Methods}

\subsubsection{Inductively Coupled Plasma Mass Spectrometry}

The rheological parameters of CPB (especially the viscosity) are closely related to the chemical environment. In order to test the changes in the chemical environment of CPB under different agitation conditions, inductively coupled plasma mass spectrometry (ICP) was used to gain insight into the pore solution chemistry, especially the concentration of calcium, sodium, and potassium ions, since they are representative of the ion concentration in the pore solution. Previous research has shown that the concentration changes of these ions are related to the hydration reaction and shrinking electric double layer, which affects the interaction force between particles.

To obtain the pore solution of CPB, a $0.50 \mu \mathrm{m}$ filter paper and a funnel were used. Prepared CPB-D sample $(100 \mathrm{~g})$ was transferred to the filter paper in the funnel, and $100 \mathrm{~g}$ of deionized water was added. 
The pore solution was obtained by vacuum filtration. The pore solution was diluted with 1:1 deionized water before the ICP test. Two bottles of about $5 \mathrm{~mL}$ samples were taken in the obtained pore solution for the ICP test. The ICP test uses SPECTRO FLAME S (Ocean Optics, Largo, FL, USA). The CPB-D prepared for each mixing speed was tested twice and the average of the two data was calculated.

\subsubsection{Rheology}

To monitor the rheological behavior of the $\mathrm{CPB}$ samples, an R/S four-paddle rotational rheometer (Brookfield RST, AMETEK Brookfieldb, Middleborough, MA, USA) was used. During the experiment, the four-paddle rotor was immersed into the slurry, spinning at a changing shearing rate. This process was under real-time monitoring and a shearing stress-rate curve was exported by software for further analysis. The temperature of the water bath equipped on this equipment remained at $20^{\circ} \mathrm{C}$.

The paste was poured into a round glass bottle, $95 \mathrm{~mm}$ in diameter and $115 \mathrm{~mm}$ in height, to a level of $90 \mathrm{~mm}$. The bottle was then fastened after putting the mixing rotor (VT-40-20) of the Brookfield RST into the paste and the flow curve test was performed at a CSR (control shearing rate) mode by raising the rate from 0 to $120 \mathrm{~s}^{-1}$ in increments of $1 \mathrm{~s}^{-1}$ via a step-up approach. Although the CPB has thixotropic properties, the recovery time of the microstructure was much longer than the time required for the breakdown. The time required for the rheological test was very short, and the shear rate was less than the mixing process, and it can be considered that the microstructure breakdown by the mixing was not recovered. Therefore, from a general view, the paste of unclassified tailings borders on a Bingham fluid and thus Equation (2) could be used for data fitting [39]. The slope and intercept were obtained through the least squares regression. In order to ensure a steady shear stress condition, the curve in which the shear rate was increased from 20 to $120 \mathrm{~s}^{-1}$ was selected for fitting.

$$
\tau=\tau_{0}+\eta \dot{\gamma}
$$

Equation (2) represents the Bingham model: $\tau$ represents the shear stress, $\mathrm{Pa} ; \tau_{0}$ represents the yield stress, $\mathrm{Pa} ; \eta$ represents the plastic viscosity, $\mathrm{Pa} \cdot \mathrm{s} ; \dot{\gamma}$ represents the shear rate, $\mathrm{s}^{-1}$.

To verify the reproducibility of the experiment, two tests were conducted for each type of mixture and the average value was adopted. For example, 12 samples were prepared for CPB-A to be stirred at 6 different speeds in Step 4. A representative set of flow curves is shown to indicate the rheology of the material.

\section{Results and Discussion}

\subsection{The Chemical Environment Changes of $C P B$}

As stated in the introduction, high mixing intensity causes structural breakdown to dissolve more hydration products into the pore solution. To verify that this conjecture is correct, ICP was used to analyze the ion concentrations of the pore solution. Figure 6 shows ion concentrations in CPB-D prepared with different mixing speeds and the error bars in the graph represent the range of experimental results.

As shown in Figure 6, when the mixing speeds were between 300 and $400 \mathrm{rpm}$, the concentrations of ions tend to be in a trough. However, when the mixing speed exceeds $500 \mathrm{rpm}$, they show a significant increase, especially calcium ions. This change in ion concentration was due to the intensifying of the mixing speed since the cement-based material static curing for $30 \mathrm{~min}$ after preparation did not cause a significant change in ion elution [40]. This increase of the initial dissolution could be caused by the consecutive repetition of breakdown and restoration of the double electrode layers of particles.

As we know, the rheological properties of CPB are influenced by its microstructure [41]. However, when $\mathrm{CPB}$ is prepared at different mixing speeds, changes are likely to occur to its microstructural state because the concentrations of ions affect the microstructural rebuilding and breaking. Therefore, different mixing speeds change the chemical environment of the $\mathrm{CPB}$, affect the aggregation kinetics of the particles, and may ultimately affect the rheological properties. 


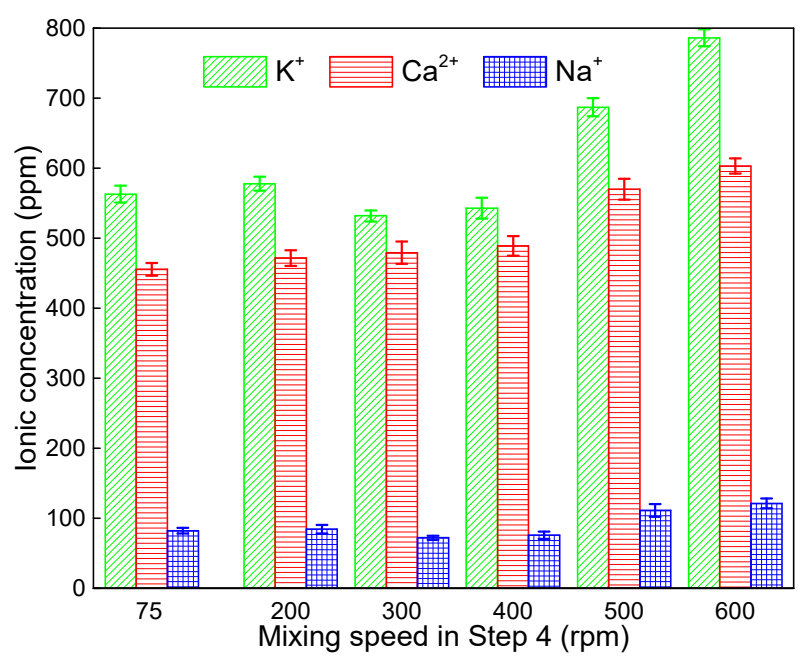

Figure 6. Results of the inductively coupled plasma mass spectrometry (ICP) test for CPB-D.

\subsection{Rheological Properties}

The experimental rheological curves are illustrated in Figure 7. Besides, from the flow curves, the Bingham parameters of yield stress and plastic viscosity were calculated using a fitted curve to the experimental data points. The rheograph in Figure 8 depicts the Bingham parameters as a function of the mixing speed in the high shear mixer, and the values in the graph represent the average values of the duplicate tests and the error bars in the graph represent the range of experimental results. In the sub-plots of Figure 7, each curve corresponds to a mixing speed of six different levels in Step 4 that was set for specimen preparation. Consistent with expectations, with an increase in the solids content, the CPB samples tended to possess a higher viscosity and yield stress but poorer flowability (except CPB-D). A higher solids content means the decrease in the spacing between particles and the increase in the interaction force, resulting in growing flow resistance in CPB. A synergistic effect of the mixing speed, solids content, and cement content used appeared to control the rheological behavior of CPB. It is known that the mixing intensity plays an important role in rheological properties of $\mathrm{CPB}$, as shown in Figure 8, which, however, was often ignored or barely commented.

The experimental results indicate that the effect on the rheological properties of the paste was not obvious before the speed reaching $200 \mathrm{rpm}$, and once exceeding $200 \mathrm{rpm}$, the viscosity and yield stress reduced significantly and the flowability was enhanced in some CPB samples. Thus, the paste could be deemed having been "activated" or dispersed and the paste presented shear-thinning characteristics. It is true that the CPB in the field where it was prepared by a higher mixing speed, had better fluidity than in laboratory experiments where it was prepared by hand mixing.

However, a higher mixing intensity does not always correspond to a better flowability. Contrary to what is widely believed, it was indicated from the results that for mixing speeds exceeding 300-400 rpm, the viscosity and yield stress increased and the fluidity deteriorated. Such non-Newtonian flow behavior of paste is thought to be caused by changes in particle arrangements [42]. Compared with Newtonian fluids, such as water, the rheological behavior of $\mathrm{CPB}$ is complicated under different mixing speeds as tiny particles are suspended in the liquid. The results, as shown in Figure 8, also show that the effect of mixing speeds on the rheological properties was more sensitive in cemented paste backfill with the higher cement proportion (CPB-D) than the lower one (CPB-C). 


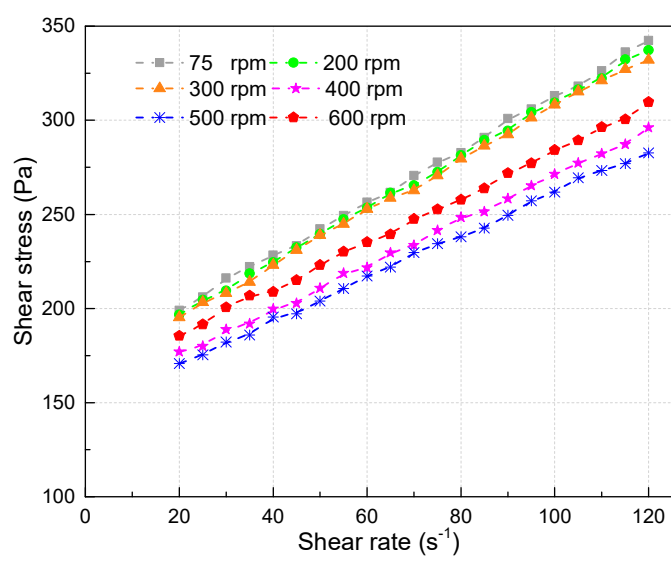

(a) CPB-A

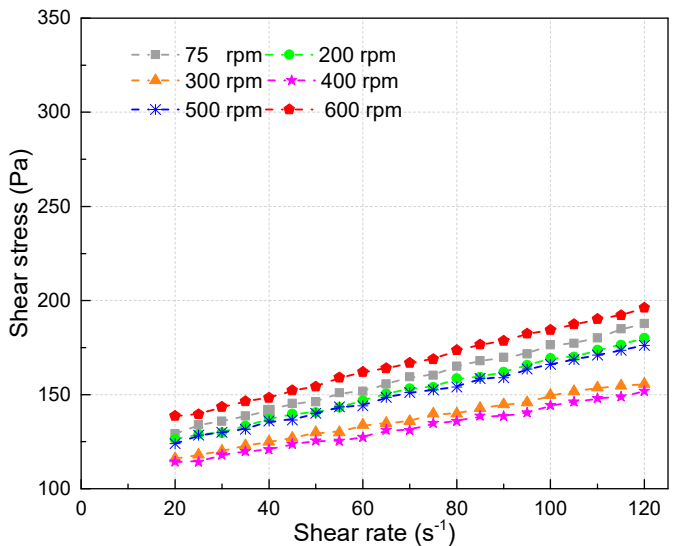

(c) CPB-C

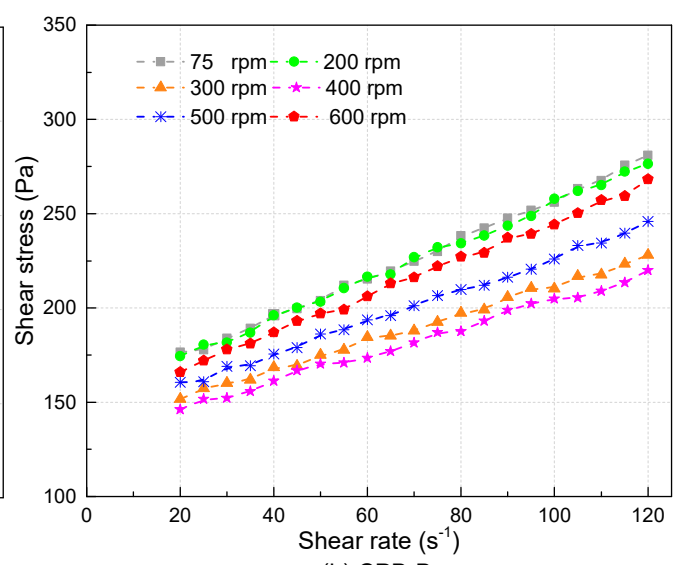

(b) CPB-B

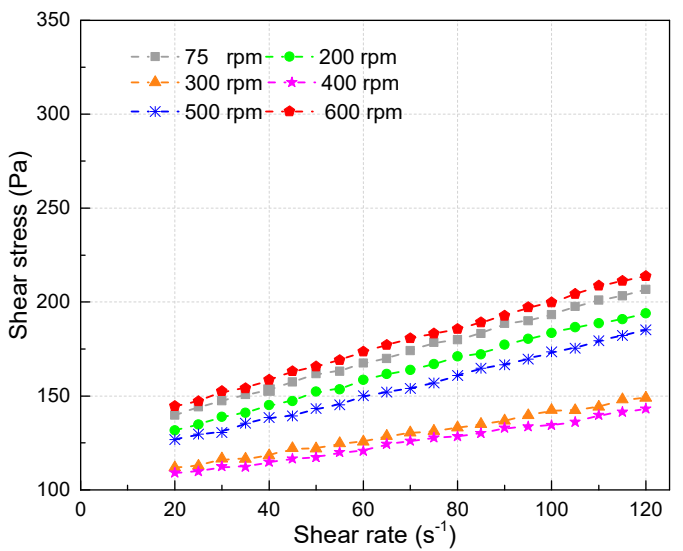

(d) CPB-D

Figure 7. Influence of mixing speed on flow curve behaviors depending on different CPBs: (a) CPB-A; (b) CPB-B; (c) CPB-C; and (d) CPB-D.
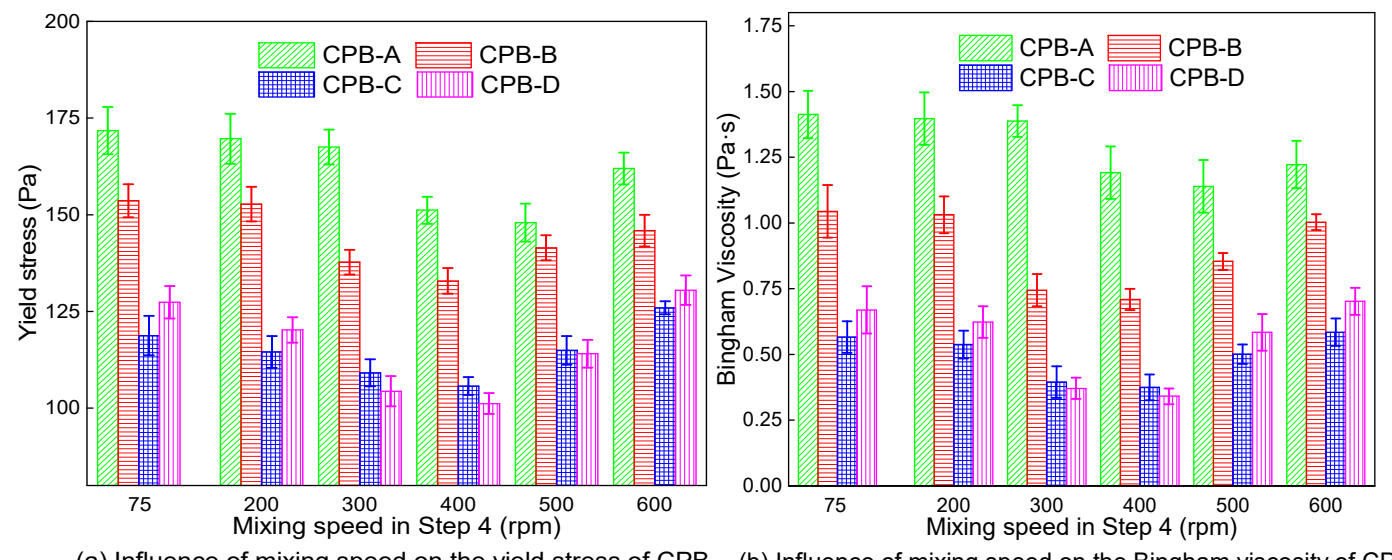

(a) Influence of mixing speed on the yield stress of CPB

(b) Influence of mixing speed on the Bingham viscosity of $\mathrm{CPB}$

Figure 8. Influence of mixing speed on the yield stress (a) and Bingham viscosity (b) of CPB.

\subsection{Thixotropic Breakdown}

As shown in Figure 8, when the mixing speed gradually accelerated from 75 to $200 \mathrm{rpm}$, the rheological properties almost remained at the same level without significant changes but showed a slight downward trend in some samples. Although CPB is commonly recognized as a Bingham fluid, it could be found that a conversion trend to shear-thinning behavior appeared in some of the CPBs as soon as the mixing speed reached above a threshold that was connected with the solids content of the samples. For the CPBs examined in this research, the threshold speed occurred between 200 and $300 \mathrm{rpm}$ for the majority of CPB, as shown in Figure 8. 
According to the PFI-theory, a speed below the threshold is not enough to destroy the cohesion between particles, thus the rheological properties of the paste will not change significantly. Figure 9a depicts that a potential energy well was determined by the particle interaction forces (colloidal interactions for $\mathrm{CPB}$ ) for each particle (i.e., an equilibrium position of minimum energy exists for each particle) [43]. The particle will not jump out of the well on condition that the mixing energy $\Delta E$ offered to the system is less than a certain value, as shown in Figure 9b. Once the shearing ceased, the elastic solid behavior occurred and the particle returns to its start position. However, when exceeding the threshold, the mixing energy was enough to disperse the particle flocculation structure (the mixing energy provided to the system was above the certain value). Therefore, the particle has the ability to get out of the well, as shown in Figure 9c, the microstructure of the paste undergoes thixotropic breakdown, and the rheological properties present shear-thinning behavior, thus the CPB system exhibits thixotropic behavior.

In the preparation of $\mathrm{CPB}$, the $\mathrm{CPB}$ is expected to be made of homogeneous distributed particles and to have a good fluidity. The corresponding threshold (minimum mixing energy) is called "the first threshold". The reversibility of this mechanism has been described by Liu et al. [44]. The attractive forces and interparticle links between the particles formed again during the rest period, and the rheology characteristics of CPB will change over time, which, however, takes a longer time compared to that of the breakdown process $[45,46]$. The potential energy well tends to be deeper at rest with time because of the Brownian motion as well as a possible evolution of the colloidal interactions [47]; the particle needs a larger amount of energy $\Delta E^{\prime}$ to get out of the well (increase of the shear stress in Figure 9d) [48].

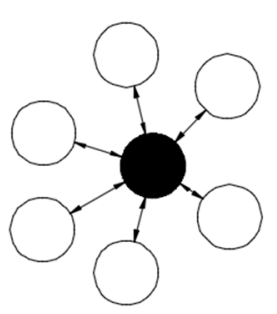

(a)

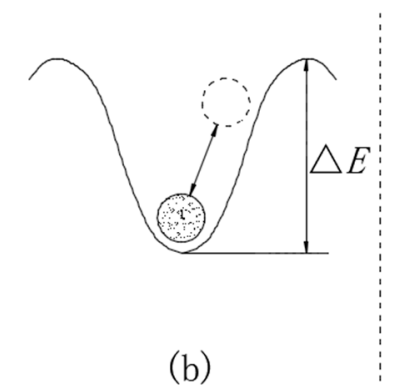

(b)
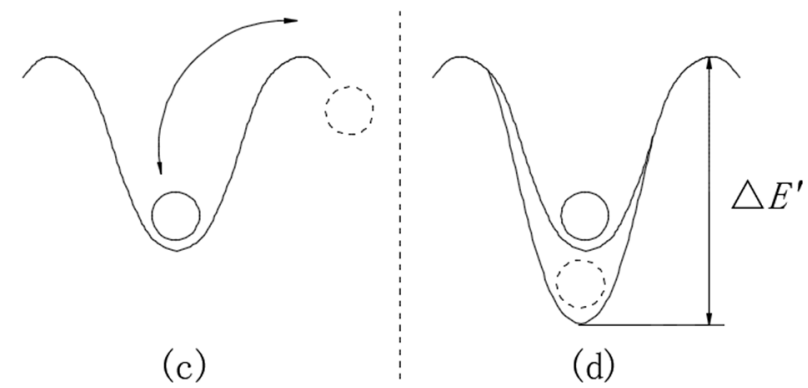

(d)

Figure 9. A simple illustration of the thixotropic behavior of CPB. (a) The particle interaction forces determine for each particle a potential energy well. (b) The particle does not leave the well. (c) The particle has the ability to get out of the well. (d) The potential energy well tends to be deeper at rest with time, the particle needs a larger amount of energy to get out of the well.

Further analyzing the experimental results of different groups (CPB-A, CPB-B, and CPB-C) in Figure 8 , we can also find that the first threshold of mixing speed increases with the solids content. The increase in the solids content of CPB reduces the distance between the particles, that is to say, as the total potential between the particles increases, the energy required to separate the particles that adsorb each other also increases. Therefore, the solids content of CPB should be fully considered when selecting a cost-effective mixing speed.

The distance between two particles is an important factor affecting the interparticle forces, and the interparticle forces could affect the microstructure (aggregation or breakdown) of the CPB. When the particles are separated under the mixing action, the repulsive force of the particles is reduced, and more ions are adsorbed to the surface of the particles [49]. Therefore, as shown in Figure 6, the concentrations of ions in the pore solution decreased when the CPB undergoes thixotropic breakdown.

On the other hand, the water-cement $(w / c)$ ratio is also a key factor affecting the rheological behavior of CPB. The solids content of CPB-D was slightly higher than that of CPB-C. The yield stress and viscosity of $C P B-D$ were larger than those of $C P B-C$ when the mixing speed was lower than the first threshold. It was consistent with the relationship between rheological parameters and solids content 
described in Section 3.2. However, we found that the rheological parameters (yield stress and viscosity) of CPB-D were less than CPB-C when the mixing speed exceeded the first threshold. Therefore, it can be assumed that the cement has a marked impact on the structural network development, which results in a more flocculated structure, and enhances the thixotropy of $\mathrm{CPB}$.

\subsection{Structural Breakdown}

Therefore, it seems that a mixing speed above the first threshold within the range of 300 to $400 \mathrm{rpm}$ was enough to disperse the CPB particles. There was no longer a significant decrease in viscosity of the paste with increasing mixing speed until reaching the second threshold of mixing intensity. For mixing speeds higher than the second threshold, the viscosity began to grow significantly in some CPBs and a shear-thickening phenomenon occurred.

It has some relation with the cement particles in CPB since a similar phenomenon also occurs in the high-speed mixing of cement slurry [50]. Since the rheological behavior of cement-based materials is affected by their changing microstructure [51] due to hydration, changes are more likely to happen to the microstructural state when the cement-based materials are prepared at varying mixing speeds [52]. The formation of agglomerates is not only due to hydration but also due to interparticle forces produced from the colloidal state of the finest cement grains [53]. As the distance between particles decreases, the thickness of electrical double layers of the particles becomes the key factor affecting the interparticle forces.

As we know, the thickness of electrical double layers of the particles is influenced by the ionic concentration $[28,54]$, and the thickness could be represented by the Debye-Hückel length equation (Equation (3)) [55]:

$$
\frac{1}{\mathcal{K}}=\sqrt{\frac{\varepsilon \varepsilon_{0} R T}{2 F^{2} I}}
$$

where $1 / \kappa$ is the thickness of electrical double layers, $\varepsilon$ is the dielectric constant (relative permittivity) of the dispersion medium, $\varepsilon_{0}$ is the permittivity of the vacuum, $T$ is the absolute temperature, $R$ is the gas constant, $I$ is the ionic strength, and $F$ is the Faraday constant. A higher ionic concentration will result in a decrease of the thickness of electrical double layers, leading to stronger/increased agglomeration [56]. Additionally, the ionic concentration is known in the ICP test. Figure 10 shows the relationship between the ionic concentration $\left(\mathrm{K}^{+}\right)$and viscosity of CPB-D. When the mixing speed exceeded $400 \mathrm{rpm}$, the ionic concentration $\left(\mathrm{K}^{+}\right)$in the pore solution increased rapidly, and the changes of the two curves in the figure were consistent. It indicates that the rheological response of CPB was consistent with the change of the chemical environment under different mixing speeds.

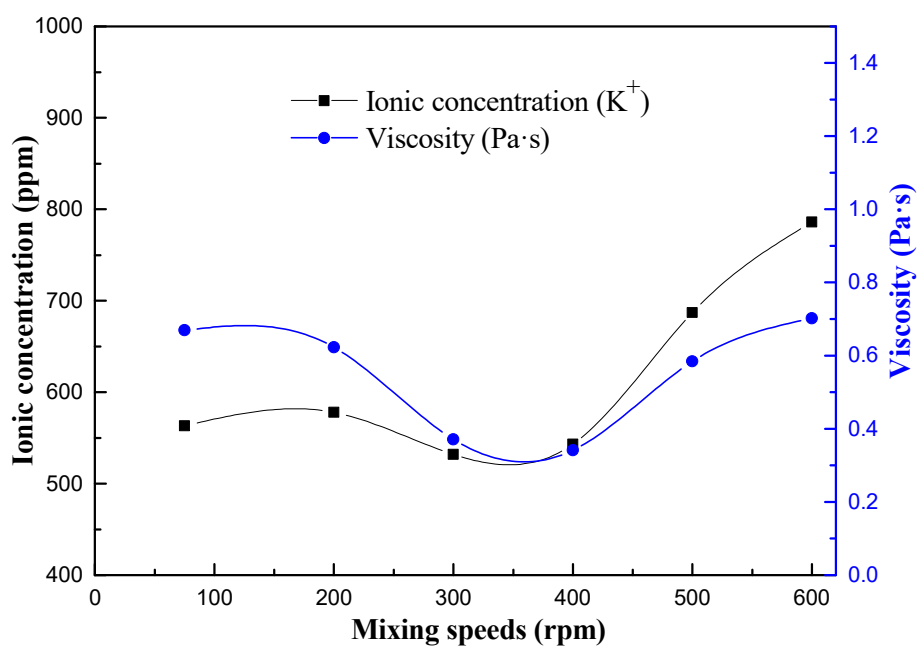

Figure 10. Relationship between ionic concentration $\left(\mathrm{K}^{+}\right)$and viscosity of CPB-D. 
This result shows that the chemical and physical qualities of the CPB system changed once the mixing speed differed. High-intensity mixing promoted the aggregation of particles. Figure 11 depicts how high-intensity mixing results in an increasing agglomeration of particles [57]. Under shear, the breakdown of particles directly leads to increased contact areas [58], and a structure of double electrode layers forms around the particle-water interface, as shown in Figure 11a. Subsequently, under the mixing action, the layer shrinks, and numerous ions and early hydration products dissolve into the water as shown in Figure 11b. According to the literature [59], the collapse of the layer reduces the electron repulsion between particles and the prevailing attraction is beneficial for aggregation of cement particles, as shown in Figure 11c. Therefore, it is believed that an increasing mixing speed during the sample preparation affects chemical reactions of $\mathrm{CPB}$ and thus transforms the agglomeration kinetics in $\mathrm{CPB}$.

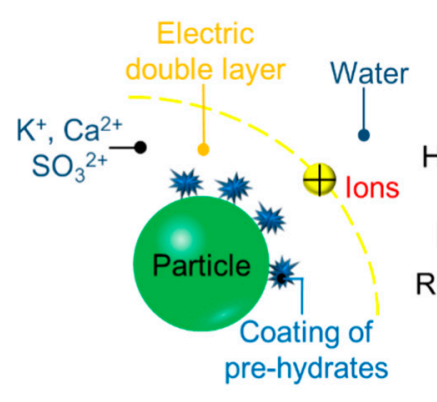

(a)

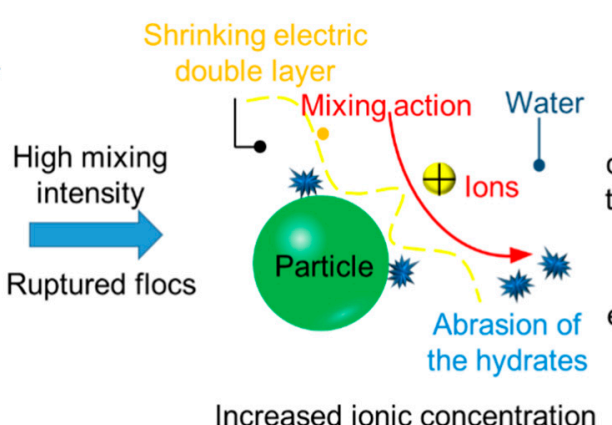

(b)

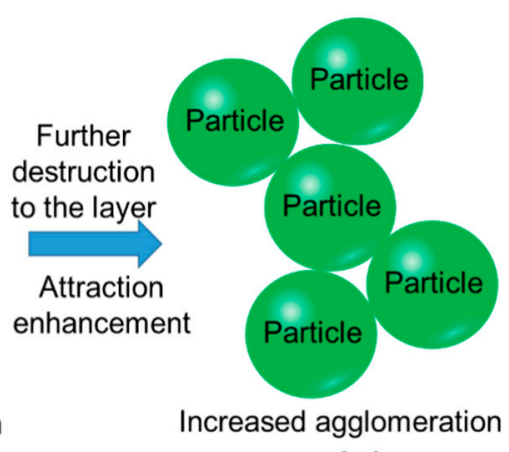

(c)

Figure 11. Schematic of the mechanism depicting how high-intensity mixing can lead to increased agglomeration. (a) Electric double layer of particle. (b) Shrinking electric double layer. (c) Particle aggregation.

Comparing the results of different groups of experiments of rheological properties, as shown in Figure 8, it can be found that the composition of CPB was an important factor affecting the shear-thickening phenomenon, and the second threshold of mixing speed increases as the solids content increases. CPBs of different compositions have different microstructures. When under shearing (mixing process), the microstructures of $\mathrm{CPB}$ respond to the shear-induced stresses with the interference of interparticle forces, leading to changes in the rheological properties. Thus, the higher sensitivity to mixing intensity (the mixing speed exceeded the second threshold) found in CPB-D as compared to $\mathrm{CPB}-\mathrm{C}$ could be ascribed to the more cement inducing changes within the $\mathrm{CPB}$ that modified the fundamental microstructural response of the CPB systems.

The structural breakdown, which seems to be less recognized and less used, describes the damaging of certain linkages chemically formed among the particles, and also includes the collapse of electrical double layers. Although this mechanism looks like "shear-thickening" behavior, it does not belong to thixotropic behavior, because the structural breakdown is not recoverable. Unfortunately, this behavior is often confused with thixotropy. To obtain a CPB with a better performance, a structural breakdown should not occur in the CPB mixing process. Considering the factors such as energy saving and high productivity, an optimal speed was proposed, and in this study, it was around 300-400 rpm.

\section{Conclusions}

This study helps us to understand the mechanism of the effect of mixing speed on CPB rheology by determining two threshold values for the mixing speed corresponding to shear thinning and (pseudo) shear thickening. The results show that the rheological behavior of pastes was greatly affected by their shear history. Changes happened in the chemical and physical nature of cemented paste backfill once the preparation mixing speed altered. 
(1) The results show that the two thresholds were related to the solids content and composition. For the majority of CPBs under examination in this study, the first threshold occurred between 200 and $300 \mathrm{rpm}$ and the second threshold between 400 and $500 \mathrm{rpm}$, respectively. When the mixing speed for CPB preparation was between the two thresholds (the shear rate was between 360 and $600 \mathrm{~s}^{-1}$ ), the paste tends to have lower viscosity and proper fluidity; this phenomenon is often referred to as thixotropic breakdown, which is a recoverable change. Considering the factors such as energy saving and high productivity, the authors proposed an optimal speed, and in this study, it was around 300-400 rpm.

(2) Far from general views, when the mixing speed for the sample preparation exceeds the second threshold, the double layer of cement particles collapses and numerous ions and early hydration products dissolve into the water, which promotes the agglomeration of particles and increases paste yield stress and Bingham viscosity. This trend was amplified in cemented paste backfill with increasing cement content.

(3) In previous studies, some researchers believed that CPB could be characterized by only two kinds of thixotropic behavior, such as shear-thickening and/or shear-thinning. The results presented in this paper suggest the observed shear-thickening was rather a pseudo shear-thickening provoked by irreversible chemical interactions between the particles. Therefore, the three concepts "structural breakdown", "thixotropic breakdown", and "thixotropic behavior" should not be confused, since a structural breakdown does not belong to thixotropic behavior and is unrecoverable.

Author Contributions: Conceptualization, L.Y. and H.W.; Data curation, H.L.; Formal analysis, X.Z.

Funding: This work received financial support from the National Key Technologies R\&D Program for the 13th Five-Year Plan (2017YFC0602903) as well as the National Natural Science Foundation of China (51374304).

Acknowledgments: The authors thank Wuyan Li and Natsuko Sagawa for their help in refining the paper.

Conflicts of Interest: The authors declare that there are no conflicts of interest regarding the publication of this paper.

\section{References}

1. Pileggi, R.G.; Studart, A.R.; Pandolfelli, V.C.; Gallo, J. How mixing affects the rheology of refractory castables-Part 2. Am. Ceram. Soc. Bull. 2001, 80, 38-42.

2. Wu, A.; Ruan, Z.; Wang, Y.; Yin, S.; Wang, S.; Wang, Y.; Wang, J. Simulation of long-distance pipeline transportation properties of whole-tailings paste with high sliming. J. Cent. South Univ. 2018, 25, 141-150. [CrossRef]

3. Fall, M.; Adrien, D.; Célestin, J.; Pokharel, M.; Touré, M. Saturated hydraulic conductivity of cemented paste backfill. Miner. Eng. 2009, 22, 1307-1317. [CrossRef]

4. Cihangir, F.; Ercikdi, B.; Kesimal, A.; Ocak, S.; Akyol, Y. Effect of sodium-silicate activated slag at different silicate modulus on the strength and microstructural properties of full and coarse sulphidic tailings paste backfill. Constr. Build. Mater. 2018, 185, 555-566. [CrossRef]

5. Wang, Y.; Fall, M.; Wu, A. Initial temperature-dependence of strength development and self-desiccation in cemented paste backfill that contains sodium silicate. Cem. Concr. Compos. 2016, 67, 101-110. [CrossRef]

6. Mahlaba, J.; Kearsley, E.; Kruger, R.; Pretorius, P. Evaluation of workability and strength development of fly ash pastes prepared with industrial brines rich in $\mathrm{SO}^{4-}$ and $\mathrm{Cl}^{-}$to expand brine utilization. Miner. Eng. 2011, 10, 1077-1081. [CrossRef]

7. Yang, L.; Wang, H.; Wu, A.; Xing, P.; Gao, W. Thixotropy of unclassified pastes in the process of stirring and shearing. J. Univ. Sci. Technol. Beijing 2016, 38, 1343-1349.

8. Zhang, Q.; Wang, X. Performance of cemented coal gangue backfill. J. Cent. South Univ. 2007, 14, $216-219$. [CrossRef]

9. Fall, M.; Célestin, J.; Pokharel, M.; Touré, M. A contribution to understanding the effect of temperatures on the mechanical properties of mine cemented tailings backfill: Experimental results. Eng. Geol. 2010, 114, 397-413. [CrossRef] 
10. Wu, D.; Cai, S. Coupled effect of cement hydration and temperature on hydraulic behavior of cemented tailings backfill. J. Cent. South Univ. 2015, 22, 1956-1964. [CrossRef]

11. Baroud, G.; Samara, M.; Steffen, T. Influence of mixing method on the cement temperature-mixing time history and doughing time of three acrylic cements for vertebroplasty. J. Biomed. Mater. Res. Part B Appl. Biomater. 2004, 68, 112-119. [CrossRef] [PubMed]

12. Wendling, A.; Mar, D.; Wischmeier, N.; Anderson, D.; Mciff, T. Combination of modified mixing technique and low frequency ultrasound to control the elution profile of vancomycin-loaded acrylic bone cement. Bone Jt. Res. 2016, 5, 26-32. [CrossRef] [PubMed]

13. Du, K.; Li, X.; Yin, Z. A new manufacture method of backfill samples in lab-Illustrated with a case study. J. Cent. South Univ. 2013, 20, 1022-1028. [CrossRef]

14. Fall, M.; Benzaazoua, M.; Saa, E. Mix proportioning of underground cemented tailings backfill. Tunn. Undergr. Space Technol. Inc. Trenchless Technol. Res. 2008, 23, 80-90. [CrossRef]

15. Ferron, R.; Shah, S.; Fuente, E.; Negro, C. Aggregation and breakage kinetics of fresh cement paste. Cem. Concr. Res. 2013, 50. [CrossRef]

16. Toutou, Z.; Roussel, N. Multi scale experimental study of concrete rheology: From water scale to gravel scale. Mater. Struct. 2006, 39, 189-199. [CrossRef]

17. Jiang, H.; Fall, M. Yield stress and strength of saline cemented tailings materials in sub-zero environments: Slag-paste backfill. Int. J. Miner. Process. 2017, 160, 68-75. [CrossRef]

18. Ghirian, A.; Fall, M. Paste Tailings Management; Springer International Publishing: Berlin/Heidelberg, Germany, 2017; pp. 22-45.

19. Wallevik, O.; Feys, D.; Wallevik, J.; Khayat, K. Avoiding inaccurate interpretations of rheological measurements for cement-based materials. Cem. Concr. Res. 2015, 78, 100-109. [CrossRef]

20. Wallevik, J. Rheological properties of cement paste: Thixotropic behavior and structural breakdown. Cem. Concr. Res. 2009, 39, 14-29. [CrossRef]

21. Wallevik, J. Particle Flow Interaction Theory-Thixotropic Behavior and Structural Breakdown. In Proceedings of the Conference on Our World of Concrete and Structures, Singapore, 14-16 August 2011; pp. 1-6.

22. Hattori, K.; Izumi, K. Rheology of Fresh Cement and Concrete. In Rheology of Fresh Cement and Concrete, Proceedings of the International Conference, London, UK; CRC Press: Boca Raton, FL, USA, 1991; pp. 83-92.

23. Hattori, K.; Izumi, K. A rheological expression of coagulation rate theory. J. Dispers. Sci. Technol. 1982, 3, 129-193. [CrossRef]

24. Tattersall, G. The rheology of Portland cement pastes. Br. J. Appl. Phys. 1955, 6, 165-167. [CrossRef]

25. Ritchie, A. The Rheology of Fresh Concrete; Pitman Books Limited: Boston, MA, USA, 1983; pp. $73-95$.

26. Wallevik, J. Rheology of Particle Suspensions: Fresh Concrete, Mortar and Cement Paste with Various Types of Lignosulfonates. Ph.D. Thesis, Norwegian University of Science and Technology, Trondheim, Norway, 2003.

27. Lapasin, R.; Papo, A.; Rajgelj, S. Flow behavior of fresh cement pastes. A comparison of different rheological instruments and techniques. Cem. Concr. Res. 1983, 13, 349-356. [CrossRef]

28. Hunter, R.J. Foundations of Colloid Science, 2nd ed.; Oxford University Press: New York, NY, USA, 2001; pp. 101-132, 131-144.

29. Williams, D.; Saak, A.; Jennings, H. The influence of mixing on the rheology of fresh cement paste. Cem. Concr. Res. 1999, 29, 1491-1496. [CrossRef]

30. Tattersall, G. Structural breakdown of cement pastes at constant rate of shear. Nature 1955, 175, 166. [CrossRef]

31. Ahari, R.; Erdem, T.; Ramyar, K. Thixotropy and structural breakdown properties of self-consolidating concrete containing various supplementary cementitious materials. Cem. Concr. Compos. 2015, 59, 26-37. [CrossRef]

32. Bullard, J.W.; Jennings, H.; Livingston, R.; Nonat, A.; Scherer, G.; Schweitzer, J.; Scrivener, K.; Thoma, J. Mechanisms of cement hydration. Cem. Concr. Res. 2011, 41, 1208-1223. [CrossRef]

33. Takahashi, K.; Bier, T.A. Westphal. Effects of mixing energy on technological properties and hydration kinetics of grouting mortars. Cem. Concr. Res. 2011, 41, 1167-1176. [CrossRef]

34. Cazacliu, B. In-mixer measurements for describing mixture evolution during concrete mixing. Chem. Eng. Res. Des. 2008, 86, 1423-1433. [CrossRef]

35. Cazacliu, B.; Roquet, N. Concrete mixing kinetics by means of power measurement. Cem. Concr. Res. 2009, 39, 182-194. [CrossRef] 
36. He, Z.; Xie, K.; Zhang, C.; Xie, C. Activating mixing technology and its application in mine backfill. GOLD 2000, 21, 18-20.

37. Landriault, D.A. Backfill in underground mining. In Underground mining methods: Engineering Fundamentals and International Case Studies; Hustrulid, R.L., Bulloch, W., Eds.; Society for Mining, Metallurgy and Exploration-SME: Lilleton, CO, USA, 2001; pp. 601-614.

38. Barnes, A.; Merseyside, L.; Carnali, O. The vane-in-cup as a novel rheometer geometry for shear thinning and thixotropic materials. J. Rheol. 1990, 34, 841-866. [CrossRef]

39. Wu, D.; Fall, M.; Cai, S. Coupling temperature, cement hydration and rheological behaviour of fresh cemented paste backfill. Miner. Eng. 2013, 42, 76-87. [CrossRef]

40. Locher, F.W. Zement-Grundlagen der Herstellung und Verwendung; Vbt Verlag Bau+ Technik: Düsseldorf, Germany, 2000.

41. Kim, W.; Yang, S. Microstructures and Rheological Responses of Aqueous CTAB Solutions in the Presence of Benzyl Additives. Langmuir 2000, 16, 6084-6093. [CrossRef]

42. Dintzis, F.; Berhow, M.; Bagley, E.; Wu, Y.; Felker, F. Shear-thickening behavior and shear-induced structure in gently solubilized starches. Cereal Chem. 1996, 73, 638-643.

43. Roussel, N. A thixotropy model for fresh fluid concretes: Theory, validation and applications. Cem. Concr. Res. 2006, 36, 1797-1806. [CrossRef]

44. Liu, X.; Wu, A.; Wang, H.; Jiao, H.; Liu, S.; Wang, S. Experimental Studies on the Thixotropic Characteristics of Unclassified-tailings Paste Slurry. J. Wuhan Univ. Technol. 2014, 38, 539-543.

45. Rudman, M.; Blackburn, M.; Graham, J.; Pullum, L. Turbulent Pipe Flow of Shear-Thinning Fluids. J. Non-Newton. Fluid Mech. 2004, 118, 33-48. [CrossRef]

46. Larson, R. Constitutive equations for thixotropic fluids. J. Rheol. 2015, 59, 595-611. [CrossRef]

47. Barnes, H. Thixotropy-A review. Non-Newton. Fluid Mech. 1997, 70, 1-33. [CrossRef]

48. Barnes, H.; Nguyen, Q. Rotating vane rheometry-A review. J. Non-Newton. Fluid Mech. 2001, 98, S0257-S0377. [CrossRef]

49. Overbeek, J. Interparticle forces in colloid science. Powder Technol. 1984, 37, 195-208. [CrossRef]

50. Han, D.; Ferron, R. Influence of high mixing intensity on rheology, hydration, and microstructure of fresh state cement paste. Cem. Concr. Res. 2016, 84, 95-106. [CrossRef]

51. Nair, S.; Ferron, R. Set-on-demand concrete. Cem. Concr. Res. 2014, 57, 13-27. [CrossRef]

52. Struble, L.; Lei, W. Rheological changes associated with setting of cement paste. Adv. Cem. Based Mater. 1995, 2, 224-230. [CrossRef]

53. Erdem, K.; Khayat, K.; Yahia, A. Correlating, rheology of self-consolidating concrete to corresponding concrete-equivalent mortar. ACI Mater. J. 2010, 106, 154-160.

54. Cosgrove, T. Colloid Science: Principles, Methods and Applications; Blackwell Publishing: Ames, IA, USA, 2005; pp. 76-95.

55. Yang, M.; Neubauer, C.; Jennings, H. Interparticle potential and sedimentation behavior of cement suspensions-Review and results from paste. Adv. Cem. Based Mater. 1997, 5. [CrossRef]

56. Ferron, R. Formwork Pressure of Self-Consolidating Concrete: Influence of Flocculation Mechanisms, Structural Rebuilding, Thixotropy and Rheology. Ph.D. Thesis, Northwestern University, Evanston, IL, USA, 2008.

57. Takahashi, K.; Bier, T. Effects of mixing action on hydration kinetics and hardening properties of cement-based mortars. Cem. Sci. Concr. Technol. 2015, 69, 161-168. [CrossRef]

58. Han, D.; Ferron, R. Effect of mixing method on microstructure and rheology of cement paste. Constr. Build. Mater. 2015, 93, 278-288. [CrossRef]

59. Takahashi, K.; Bire, A. Mechanisms of Degradation in Rheological Properties Due to Pumping and Mixing. Adv. Civ. Eng. Mater. 2014, 3, 25-39. [CrossRef]

(C) 2019 by the authors. Licensee MDPI, Basel, Switzerland. This article is an open access article distributed under the terms and conditions of the Creative Commons Attribution (CC BY) license (http://creativecommons.org/licenses/by/4.0/). 